\title{
CARACTERIZAÇÃo da ÁRea Foliar de Merremia aegyptia
}

\author{
Determination of the Leaf Area of Merremia aegyptia
}

\author{
BIANCO, S. ${ }^{2}$, CARVALHO, L.B. ${ }^{3}$, PANOSSO, A.R. ${ }^{3}$ e BIANCO, M.S. ${ }^{4}$
}

\begin{abstract}
RESUMO - O conhecimento da área foliar de plantas daninhas pode auxiliar o estudo das relações de interferência entre elas e as culturas agrícolas. O objetivo desta pesquisa foi determinar uma equação matemática que estime a área foliar de Merremia aegyptia, a partir da relação entre as dimensões lineares dos limbos foliares. Folhas da espécie foram coletadas de diferentes locais na Universidade Estadual Paulista, Jaboticabal, Brasil, medindo-se o comprimento (C), a largura máxima (L) e a área foliar de três tipos de folíolos. Foram estimadas equações lineares $\left(\mathrm{Y}=a^{*} \mathrm{X}\right)$ para cada tipo de folíolo. A área foliar da espécie pode ser estimada pelo somatório das áreas dos limbos foliares de cada tipo de folíolo, por meio da equação $\mathrm{AF}_{\text {est }}=0,547470(\mathrm{X})+1,145298(\mathrm{Y})+1,244146(\mathrm{Z})$, em que $\mathrm{X}$ indica $\mathrm{C}^{\star} \mathrm{L}$ do foliolo principal e $\mathrm{Y}$ e $Z$ indicam $\mathrm{C}^{\star} \mathrm{L}$ médios dos foliolos primário e secundário, respectivamente.
\end{abstract}

Palavras-chave: planta daninha, crescimento, corda-de-viola.

\begin{abstract}
Weed leaf area knowledge can provide a support to study the relationships of interference between weeds and crops. The objective of this research was to determine a mathematical equation to estimate the leaf area of Merremia aegyptia based on the relation among the linear measures of the leaf blades. Leaves of this species were gathered from different places at Sao Paulo State University, Jaboticabal, Brazil, by measuring length (L), maximum width (W,) and leaf area of three types of leaflets. Linear equations $\left(Y=\boldsymbol{a}^{*} X\right)$ were estimated for each type of leaflet. The leaf area of the species can be estimated by the sum of the leaf areas of each leaflet type according to the equation $L A_{\text {est }}=0.547470(X)+1.145298(Y)+1.244146(Z)$, where $X$ indicates $L * W$ of the main leaflet, and $Y$ and $Z$ indicate the medium $L * W$ of the primary and secondary leaflets, respectively.
\end{abstract}

Keywords: weed, growth, hairy woodrose.

\section{INTRODUÇÃO}

Merremia aegyptia, Convolvulacea, é uma espécie vegetal de hábito trepador que pode acarretar sérios problemas à colheita mecanizada em áreas de cultivo agrícola (Kissmann \& Groth, 1999). No Brasil, além de ocorrer como planta daninha (Silva et al., 2004), tem sido utilizada como adubo verde (Lima et al., 2007), planta forrageira (Pereira et al., 2007) e planta ornamental (Azania et al., 2003).
Estudos básicos a respeito de reprodução, crescimento, desenvolvimento, exigência nutricional, respostas aos sistemas de controle e outros aspectos são necessários para melhor compreensão da biologia e escolha de métodos de manejo de espécies daninhas. Na maioria desses estudos, o conhecimento da área foliar é fundamental, pois é uma das características mais importantes na avaliação do crescimento vegetal, além de auxiliar na compreensão de relações de interferência entre plantas daninhas e cultivadas (Bianco et al., 2008).

1 Recebido para publicação em 6.11.2008 e na forma revisada em 11.12.2009.

2 Prof. Livre Docente do Dep. de Biologia Aplicada à Agropecuária, Faculdade de Ciências Agrárias e Veterinárias, Universidade Estadual Paulista - FCAV/UNESP, Via de Acesso Prof. Paulo Donato Castellane s/n, 14884-900 Jaboticabal-SP, <sbianco@fcav.unesp.br>; ${ }^{3}$ Doutorando do Programa de Pós-Graduação em Produção Vegetal, FCAV/UNESP, Jaboticabal-SP, <agrolbcarvalho@gmail.com>, <arpanosso@yahoo.com.br>; ${ }^{4}$ Mestrando do Programa de Pós-Graduação em Produção Vegetal, FCAV/UNESP, Jaboticabal-SP, <matbianco2004@yahoo.com.br>. 
A estimativa da área foliar por meio de equações matemáticas tem sido utilizada com boa precisão, sendo um método fácil, rápido e não destrutivo, tornando-se importante para avaliar o crescimento das plantas em campo (Bianco et al., 2007). Equações de regressão, relacionando área foliar real com características dimensionais lineares das folhas, para estimativa de área foliar têm sido utilizadas com sucesso tanto em plantas cultivadas (Pedro Júnior et al., 1986; Silva et al., 1998; Queiroga et al., 2003) quanto em plantas daninhas (Carvalho \& Christoffoleti, 2007; Bianco et al., 2007, 2008).

O objetivo desta pesquisa foi determinar uma equação matemática que pudesse estimar adequadamente a área foliar de $M$. aegyptia, a partir da relação entre as dimensões lineares dos limbos foliares.

\section{MATERIAL E MÉTODOS}

Esta pesquisa foi realizada na Faculdade de Ciências Agrárias e Veterinárias da Universidade Estadual Paulista (FCAV/ UNESP), campus de Jaboticabal. As folhas utilizadas no estudo foram coletadas em meados do mês de maio de 2008, em diferentes agroecossistemas da FCAV/UNESP, buscando amostrar plantas de $M$. aegyptia nas diferentes condições ecológicas em que as espécies podem ocorrer dentro de ambientes agrícolas. Foram coletados 100 limbos foliares dos três tipos de folíolos (Figura 1), considerando todas as folhas das plantas, desde que não apresentassem deformações oriundas de fatores externos, como pragas, doenças e outros fatores.

Em cada local de amostragem, 10 a 20 folhas de diferentes plantas foram coletadas e, em seguida, rapidamente levadas ao Laboratório de Biologia e Manejo de Plantas Daninhas da FCAV/UNESP, para determinação do comprimento do limbo foliar ao longo da nervura principal (C) e da largura máxima do limbo foliar perpendicular à nervura principal (L), de cada tipo de folíolo. A seguir, a área real de cada folíolo (AF) foi determinada com a utilização do aparelho eletrônico "Portable Area Meter" Licor mod. L1 - 3000.

Para o estudo da relação entre a área do limbo foliar e as dimensões dos folíolos, foi realizada a estimativa das equações lineares para cada tipo de folíolo, testando-se a equação linear: $\mathrm{Y}=a^{*} \mathrm{X}$, em que $\mathrm{Y}$ é a estimativa do valor da área do limbo foliar; $a$, um parâmetro de reta que corresponde ao percentual de equivalência entre as áreas foliares; e X, o produto do comprimento (C) pela largura (L). Nesse caso, supõe-se que a área foliar seja proporcional a um retângulo $\mathrm{C}^{*} \mathrm{~L}$ (Peressin et al., 1984). Essa equação foi escolhida porque Bianco et al. (2005, 2007, 2008), entre outros, concluíram que a equação linear que passa pela origem é satisfatória para estimar a área foliar, além de ser aquela de melhor aplicação prática.

A análise das retas de ajuste foi feita por meio da comparação dos intervalos de confiança obtidos para o parâmetro $a$, a $5 \%$ de significância, sendo consideradas iguais as equações que apresentassem sobreposição do intervalo de confiança das retas. No caso da não ocorrência de sobreposição dos intervalos de confiança, as retas foram consideradas diferentes; nesse caso, a análise de ajuste das retas deve ser realizada de forma separada, uma para cada tipo de folíolo, sem levar em consideração a totalidade dos dados amostrais (principais + primários + secundários).

Para averiguar a correlação entre os valores reais e estimados pelas equações, procedeu-se ao teste de correlação de SpearmanRank. No tocante aos valores dos resíduos

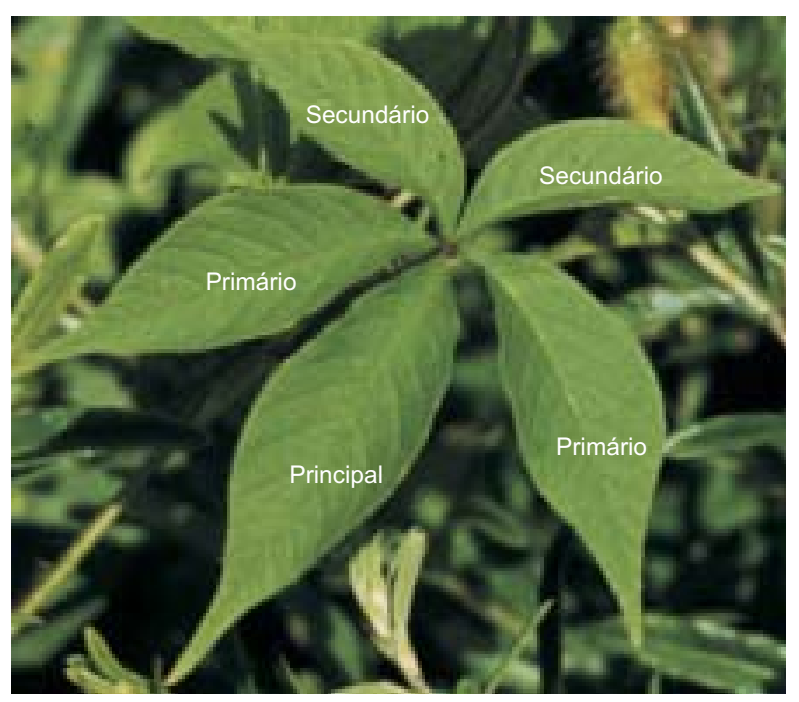

Figura 1 - Representação esquemática da folha composta por três tipos de folíolos de Merremia aegyptia. 
resultantes do teste de correlação, realizouse o teste de normalidade de Shapiro-Wilk, para verificar se havia distribuição normal dos resíduos.

\section{RESULTADOS E DISCUSSÃO}

Há pouca informação na literatura referente à biologia de plantas daninhas, e nenhum trabalho foi encontrado a respeito de $M$. aegyptia. Comparando os valores médios de área foliar dessa espécie com os de outras Convolvulacea infestantes de agroecossistemas já estudadas, ressalta-se que $M$. aegyptia apresentou maior área foliar $\left(74,61 \mathrm{~cm}^{2}\right)$ que Ipomoea hederifolia $\left(29,76 \mathrm{~cm}^{2}\right)$ e Ipomoea nil $\left(21,28 \mathrm{~cm}^{2}\right)$ (Bianco et al., 2007). Com maior área foliar, a planta pode interceptar maior quantidade de luz solar em relação àquelas com que está competindo, porém sua eficiência depende, logicamente, do potencial fotossintético da espécie.

Quanto à distribuição da área dos limbos foliares em relação ao tamanho, 68\% dos folíolos principal e primário apresentaram valores entre 10,01 e $30,00 \mathrm{~cm}^{2}$, enquanto o folíolo secundário, apenas $30 \%$, dos quais $29 \%$ estavam entre 10,01 e $20,00 \mathrm{~cm}^{2}$ (Tabela 1); na faixa de 00,01 a $10,00 \mathrm{~cm}^{2}$ foram encontrados $70 \%$ dos folíolos secundários, $9 \%$ de principal e 20\% de primários; além disso, 23\% e $12 \%$ dos foliolos principal e primário, respectivamente, apresentaram mais de $30,00 \mathrm{~cm}^{2}$ de área.

Para testar a hipótese da nulidade, de que não existem diferenças significativas entre os folíolos com relação às dimensões, foi realizada a análise de variância, por meio do teste $\mathrm{F}$. Esse teste foi significativo a $5 \%$ de probabilidade; portanto, rejeitou-se a hipótese da nulidade, concluindo-se que existem diferenças significativas entre os folíolos com relação às dimensões. As médias das variáveis comprimento, largura e área foliar, de cada tipo de folíolo, foram comparadas pelo teste de Tukey a $5 \%$ de probabilidade (Tabela 2). Os resultados indicam que os folíolos principais apresentam dimensões significativamente maiores quando comparados aos demais folíolos, com área foliar média igual a 22,99 $\mathrm{cm}^{2}$. As dimensões dos folíolos primários apresentaram valores intermediários, com área foliar média igual a
$17,27 \mathrm{~cm}^{2}$, e os folíolos secundários mostraram as menores dimensões, com área foliar média igual a $8,53 \mathrm{~cm}^{2}$. Além disso, não foram observadas sobreposições dos intervalos de confiança para o parâmetro de ajuste de reta (a) das três equações (folíolos principais, primários e secundários) (Tabela 3); portanto, não foi observada equivalência entre as equações. Nesse caso, as estimativas das equações lineares foram obtidas independentemente.

Assim, a estimativa da equação linear foi realizada para cada tipo de folíolo individualmente, resultando em três equações (Tabela 3), que são representadas graficamente na Figura 2. Houve dispersão muito pequena dos dados em relação às retas ajustadas, sugerindo que as equações podem representar a área foliar muito satisfatoriamente. Todos os ajustes apresentaram altos valores de

Tabela 1 - Distribuição percentual de 100 limbos foliares dos três tipos de folíolos de Merremia aegyptia, em relação às faixas de tamanho

\begin{tabular}{|c|c|c|c|}
\hline \multirow{2}{*}{$\begin{array}{c}\text { Tamanho } \\
\left(\mathrm{cm}^{2}\right)\end{array}$} & \multicolumn{3}{|c|}{ Percentagem de Folíolos } \\
\cline { 2 - 4 } & Principal & Primário & Secundário \\
\hline$[00,01-05,00]$ & 1 & 2 & 21 \\
\hline$[05,01-10,00]$ & 8 & 18 & 49 \\
\hline$[10,01-20,00]$ & 47 & 55 & 29 \\
\hline$[20,01-30,00]$ & 21 & 13 & 1 \\
\hline$[30,01-40,00]$ & 9 & 10 & - \\
\hline$[40,01-50,00]$ & 11 & 1 & - \\
\hline$[>50,01]$ & 3 & 1 & - \\
\hline
\end{tabular}

Tabela 2 - Valores médios de comprimento (cm), largura máxima $(\mathrm{cm})$ e área do limbo foliar $\left(\mathrm{cm}^{2}\right)$ dos três tipos de folíolos de Merremia aegyptia

\begin{tabular}{|l|c|c|c|}
\hline \multirow{2}{*}{ Folíolo } & \multicolumn{3}{|c|}{ Média $^{{ }^{\prime}}$} \\
\cline { 2 - 4 } & Comprimento & $\begin{array}{c}\text { Largura } \\
\text { máxima }\end{array}$ & Área foliar \\
\hline Principal & $9,988 \mathrm{a}$ & $3,905 \mathrm{a}$ & $22,998 \mathrm{a}$ \\
\hline Primário & $8,643 \mathrm{~b}$ & $3,195 \mathrm{~b}$ & $17,275 \mathrm{~b}$ \\
\hline Secundário & $5,842 \mathrm{c}$ & $2,128 \mathrm{c}$ & $8,531 \mathrm{c}$ \\
\hline CV $(\%)$ & 25,390 & 34,760 & 62,670 \\
\hline DMS $(\mathrm{cm})$ & 0,690 & 0,356 & 3,397 \\
\hline
\end{tabular}

1/ Médias seguidas pela mesma letra não se diferenciam pelo teste de Tukey $(\mathrm{p}<0,05)$. 
Tabela 3 - Parâmetro $a$ da equação de regressão, erro-padrão, coeficiente de determinação $\left(\mathrm{R}^{2}\right)$ e intervalo de confiança (IC) a 5\% de significância, para a estimativa da área foliar dos diferentes tipos de folíolos de Merremia aegyptia a partir das dimensões comprimento e largura máxima do limbo foliar

\begin{tabular}{|l|c|c|c|c|c|}
\hline \multirow{2}{*}{ Folíolo } & \multirow{2}{*}{$a$} & \multirow{2}{*}{ Erro-padrão } & \multirow{2}{*}{$\mathrm{R}^{2}$} & \multicolumn{2}{c|}{ IC (5\%) } \\
\cline { 4 - 6 } & & & & Mínimo & Máximo \\
\hline Principal & $0,547470^{* *}$ & 0,002656 & 0,99116458 & 0,542799 & 0,552740 \\
\hline Primário & $0,572649^{* *}$ & 0,004440 & 0,97635682 & 0,563839 & 0,581459 \\
\hline Secundário & $0,622073^{* *}$ & 0,004048 & 0,98076539 & 0,614040 & 0,630106 \\
\hline
\end{tabular}

** significativo pelo teste $\mathrm{t}$ a $1 \%$ de probabilidade.

coeficiente de determinação $\left(\mathrm{R}^{2}\right)$, indicando alta precisão nas estimativas da área foliar. Em relação ao folíolo principal, foi verificado que $99,1 \%$ das variações dos dados podem ser explicadas pela equação estimada; no folíolo primário, 97,7\%; e no secundário, 98,1\%. A análise do parâmetro de ajuste de reta indicou também que a área do limbo foliar do folíolo principal foi representada por cerca de $54,75 \%$ do produto do comprimento pela largura máxima do limbo foliar, enquanto aquela do folíolo primário foi representada por cerca de $57,26 \%$, e a do secundário, por cerca de $62,21 \%$ (Tabela 3).

A análise de correlação de SpearmanRank, aplicada sobre os valores reais de área do limbo foliar dos três tipos de folíolos e os valores estimados pelas equações, foi significativa $(\mathrm{p}<0,05)$, com coeficiente de correlação de 0,992, 0,983 e 0,981 para os folíolos principal, primário e secundário, respectivamente, indicando que existe forte correlação entre os valores reais e estimados. Além disso, o teste de normalidade de Shapiro-Wilk, realizado sobre os resíduos resultantes do teste de correlação entre os valores reais e estimados, não foi significativo para os folíolos principal $(\mathrm{p}=0,313)$, primário $(\mathrm{p}=0,186)$ e secundário $(p=0,819)$, confirmando a distribuição normal dos resíduos (Shapiro \& Wilk, 1965).

Portanto, as equações matemáticas obtidas para cada tipo de folíolo podem caracterizar satisfatoriamente a área do limbo foliar dos três tipos de folíolos de $M$. aegyptia. Assim, optou-se pela determinação de uma equação geral que estimasse a área foliar total de $M$. aegyptia em função da área dos três tipos de folíolos, utilizando o somatório da área do limbo foliar de cada tipo de folíolo. Assim, a equação geral que estima a área foliar (AFest) de $M$. aegyptia pode ser descrita por:

em que $\mathrm{Cpr}, \mathrm{Cpm}$ e Csc indicam valores de comprimento ao longo da nervura principal do limbo foliar; e Lpr, Lpm e Lsc indicam valores de largura máxima do limbo foliar, nos folíolos principal, primário e secundário, respectivamente.

Como a folha de $M$. aegyptia é composta por cinco folíolos: um principal, dois primários e dois secundários (Figura 1), para folíolos primários e secundários devem ser aplicados na equação os valores médios de comprimento e largura do limbo foliar.

O teste de correlação de Spearman-Rank, realizado sobre os valores reais de área foliar total e estimados pela equação geral, foi significativo $(\mathrm{p}<0,05)$, com coeficiente de correlação de 0,996, indicando forte correlação entre os valores reais e estimados (Spearman, 1904). Além disso, o teste de normalidade de Shapiro-Wilk, realizado sobre os valores de resíduos resultantes da análise de correlação, não foi significativo $(\mathrm{p}>0,05)$ para a área foliar total ( $p=0,619)$, indicando que há distribuição normal dos resíduos (Shapiro \& Wilk, 1965).

Os resultados indicam que a equação matemática $\mathrm{AF}_{\text {est }}=0,54747(\mathrm{X})+1,145298(\mathrm{Y})$ $+1,244146(Z)$, em que $X$ indica $C^{*} L$ do foliolo principal e $\mathrm{Y}$ e $\mathrm{Z}$ indicam $\mathrm{C}^{*} \mathrm{~L}$ médios dos foliolos primário e secundário, respectivamente, pode estimar de maneira satisfatória a área foliar de $M$. aegyptia. 


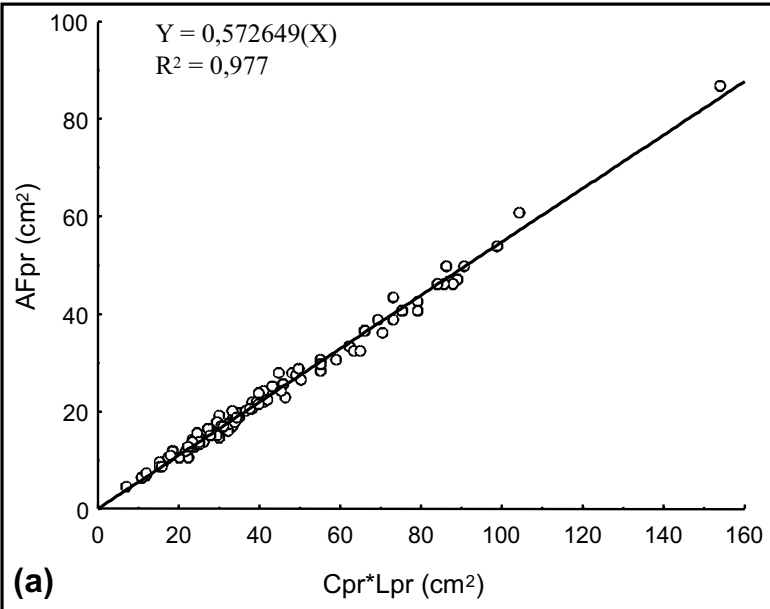

(a)
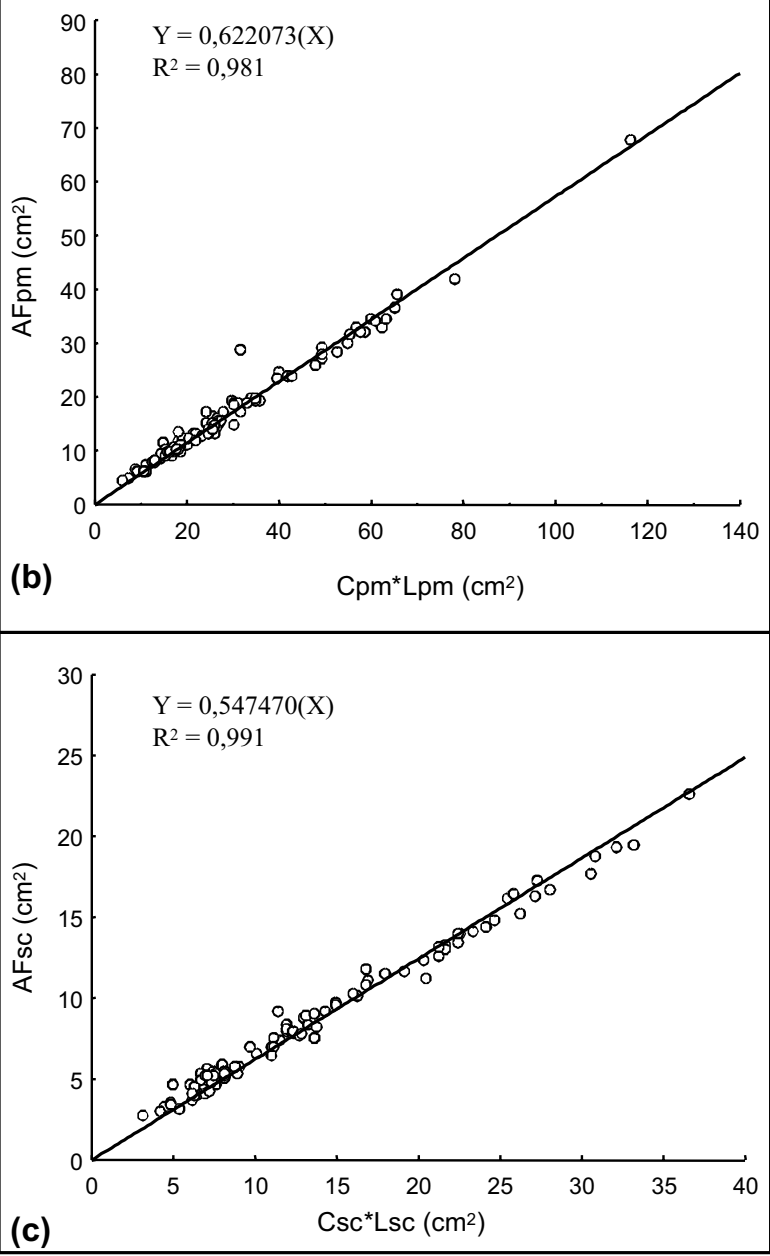

Figura 2 - Relação entre a área do limbo foliar dos folíolos principal (AFpr), primário (AFpm) e secundário (AFsc) de Merremia aegyptia, em que (a) comprimento (Cpr) e largura máxima (Lpr) do folíolo principal, (b) comprimento (Cpm) e largura máxima (Lpm) do folíolo primário e (c) comprimento (Csc)e largura máxima (Lsc) do folíolo secundário.

\section{LITERATURA CITADA}

AZANIA, A. A. P. M. et al. Métodos de superação de dormência em sementes de Ipomoea e Merremia .

Planta Daninha, v. 21, n. 2, p. 203-209, 2003.

BIANCO, S. et al. Estimativa da área foliar de Ipomoea hederifolia e Ipomoea nil Roth. usando dimensões lineares do limbo foliar. Planta Daninha, v. 25, n. 2, p. 325-329, 2007.

BIANCO, S.; PITELLI, R. A.; BIANCO, M. S. Estimativa da área foliar de Brachiaria plantaginea usando dimensões lineares do limbo foliar. Planta Daninha, v. 23, n. 4, p. 597-601, 2005.

BIANCO, S. et al. Estimativa da área foliar de Sida cordifolia e Sida rhombifolia usando dimensões lineares do limbo foliar. Planta Daninha, v. 26, n. 4, p. 807-813, 2008.

CARVALHO, S. J. P.; CHRISTOFFOLETI, P. J. Estimativa da área foliar de cinco espécies do gênero Amaranthus usando dimensões lineares do limbo foliar. Planta Daninha, v. 25, n. 2, p. 317-324, 2007.

KISSMANN, K. G.; GROTH, D. Plantas infestantes e nocivas. 2.ed. São Paulo: BASF, 1999. Tomo II. 978 p.

LIMA, G. K. L. et al. Utilização da jitirana em cobertura como adubo verde no desenvolvimento do feijão mungo. R. Bras. Agroecol., v. 2, n. 2, p. 1405-1407, 2007.

PEDRO JÚNIOR, M. J.; RIBEIRO, I. J. A.; MARTINS, F. P. Determinação da área foliar em videira cultivar Niagara Rosada. Bragantia, v. 45, n. 1, p. 199-204, 1986.

PEREIRA, E. W. L. et al. Superação de dormência em sementes de jitirana (Merremia aegyptia). Caatinga, v. 20, n. 2, p. 59-62, 2007

PERESSIN, V. A.; PITELLI, R. A.; PERECIN, D. Métodos para estimativa da área foliar de plantas daninhas. 4. Cassia tora L. Planta Daninha, v. 7, n. 2, p. 48-52, 1984.

QUEIROGA, J. L. et al. Estimativa da área foliar do feijãovagem (Phaseolus vulgaris L.) por meio da largura máxima do folíolo central. Hortic. Bras., v. 21, n. 1, p. 64-68, 2003.

SHAPIRO, S. S.; WILK, M. B. An analysis of variance test for normality (complete samples). Biometrika, v. 52, n. 3-4, p. 591-611, 1965.

SILVA, N. F. et al. Modelos para estimar a área foliar de abóbora por meio de medidas lineares. R. Ceres, v. 45, n. 259, p. 287-291, 1998.

SILVA, P. S. L. et al. Floristic composition and growth of weeds under custard apple (Annona squamosa) progenies. Planta Daninha, v. 22, n. 4, p. 529-537, 2004.

SPEARMAN, C. The proof and measurement of association between two things. Am. J. Psychol., v. 15, n. 1, p. 72-101, 1904. 